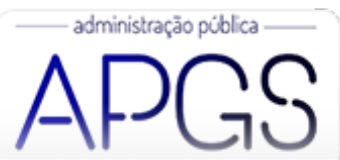

Administração Pública e Gestão Social ISSN: 2175-5787

apgs@ufv.br

Universidade Federal de Viçosa

Brasil

\title{
Configurações Subjetivas dos Servidores da Receita Federal Diante da Ideologia Gerencialista
}

\author{
de Fátima Pinto, Juliana; Paes de Paula, Ana Paula \\ Configurações Subjetivas dos Servidores da Receita Federal Diante da Ideologia Gerencialista \\ Administração Pública e Gestão Social, vol. 12, núm. 3, 2020 \\ Universidade Federal de Viçosa, Brasil \\ Disponible en: http://www.redalyc.org/articulo.oa?id=351563312014
}

Esta obra está bajo una Licencia Creative Commons Atribución-NoComercial-SinDerivar 3.0 Internacional. 


\title{
Configurações Subjetivas dos Servidores da Receita Federal Diante da Ideologia Gerencialista
}

\author{
Subjective Configurations of Federal Revenue Servers in the face of Managerial Ideology \\ Configuración Subjetiva de los Servidores de la Secretaria de Hacienda Ante la Ideología Gerencialista
}

Juliana de Fátima Pinto

Universidade Federal do Espirito Santo, Brasil

Redalyc: http://www.redalyc.org/articulo.oa?

jufapinto@gmail.com

Ana Paula Paes de Paula

UFMG, Brasil

appp.ufmg@gmail.com

\section{Resumo:}

O objetivo do trabalho foi compreender as configuraçóes subjetivas compartilhadas pelo servidor da Receita Federal do Brasil (RFB) decorrentes de sua atuação em um trabalho marcado pela hegemonia da ideologia gerencialista. A epistemologia e metodologia qualitativa apoiaram-se na teoria da subjetividade de Rey $(2003,2005)$. O método foi o estudo de caso na $6^{a}$ Região Fiscal da RFB, na cidade de Belo Horizonte, entre os anos de 2016 e 2017. As informações foram produzidas a partir de conversações com três analistas tributários e três auditores fiscais. Foram definidas cinco configuraçõos subjetivas: Competitividade por atribuições, bônus produtividade, filiação sindical, mudança tecnológica e insatisfação. Concluiu-se que o gerencialismo perpassa as configurações subjetivas dos servidores. Por conseguinte, é necessário dar voz às singularidades para construir alternativas capazes de romper com os conflitos, rivalidades e sofrimentos presentes na subjetividade social.

Palavras-Chave: Configurações subjetivas, Gerencialismo, Administração pública, Ideologia.

\section{Abstract:}

This study aimed to understand the shared subjective configurations of the Brazilian Federal Revenue Service's (RFB) server in a work marked by the hegemony of managerialist ideology. The epistemology and qualitative methodoly used were based in the Theory of Subjectivity proposed by Rey $(2003,2005)$. The method used was the case study. The research was done in a RFB unit at Belo Horizonte, in the state of Minas Gerais, in the Southeast Region of Brazil, from 2016 to 2017. Empirical data were produced through conversations with three tax analysts and three tax auditors. Five subjective configurations were defined: Competitiveness by attributions, productivity bonus, union membership, technological changes, dissatisfaction in the RFB. It was concluded that managerialism permeates the subjective configurations of the servers. In this way, it is necessary to give voice to the singularities to construct alternatives that break up with the conflicts, rivalries and sufferings present in the social subjectivity.

KeYwORDS: Subjective configurations, Managerialism, Public administration, Ideology.

\section{RESUMEN:}

El objetivo de este trabajo fue comprender las configuraciones subjetivas compartidas por el servidor de la Secretaria de Hacienda de Brasil (RFB) derivadas de su actuación en un trabajo marcado por la ideología gerencialista. La epistemología y metodología cualitativa se apoyó en la teoría de la subjetividad de Rey $(2003$, 2005). El método fue el estudio de caso en la RFB, en Belo Horizonte, ciudad situada en la región Sudeste de Brasil, entre 2016 y 2017. Las informaciones fueron producidas a partir de conversaciones con tres analistas tributarios y tres auditores fiscales. Se definieron cinco configuraciones subjetivas: Competitividad por atribuciones, bonificación de productividad, filiación sindical, cambio tecnológico e insatisfacción. Se concluyó que el gerencialismo atraviesa las configuraciones subjetivas de los servidores. Por consiguiente, es necesario dar voz a las singularidades para construir alternativas capaces de romper con los conflictos, rivalidades y sufrimientos presentes en la subjetividad social.

Palabras claVe: Configuraciones subjetivas, Gerencialismo, Administración pública, Ideología. 


\section{INTRODUÇÃO}

Este estudo tem como tema o gerencialismo, ou seja, a utilização de técnicas gerenciais para administrar de forma eficiente tanto as organizações quanto a sociedade, conceito construído a partir do entendimento de Klikauer (2013a, 2013b). O gerencialismo representa a incorporação pela gestão de ideologias baseadas na ideia da competição, eficiência, lucro, metas, liderança, estratégia e qualidade (Gaulejac, 2007; Klikauer, 2013b). Este também se torna um meio para realização das reformas e das políticas neoliberais (Misoczky, Abdals, \& Damboriarena, 2017).

No Brasil, o gerencialismo ganha força com o Governo Fernando Henrique Cardoso (FHC), na década de 1990, quando a eficiência, um dos seus princípios, transformou-se em prioridade nas políticas governamentais, surgindo como solução para a melhoria dos serviços da administração pública (Brasil, 1996). Desde então, ocorreram significativas mudanças no âmbito público, seguindo Estados que vivenciaram o processo de transformação da burocracia para o gerencialismo (Paulilo, 2013).

Apesar da importância que o gerencialismo possui para o entendimento das organizações e da sociedade (Klikauer, 2013a), há uma lacuna em relação a essa temática. A falta de novas pesquisas sobre o gerencialismo e a fragilidade de estudos teóricos sobre a administração pública, devido ao afastamento dos pesquisadores da teoria das organizações desse campo específico seriam algum deles (Misoczky et al., 2017).

Além das limitações apontadas acima, as transformações advindas do gerencialismo são estudadas nos estudos organizacionais, principalmente a partir de perspectivas objetivas, buscando modelos, melhores práticas adotadas no exterior, melhor ideologia, etc. (Silveira, Palassi, \& Silva, 2013), evidenciando uma lacuna no que se refere aos estudos sob o enfoque da subjetividade. No campo de estudo da administração pública, o foco do gerencialismo tem sido o alcance ou não dos resultados, em termos quantitativos, e pouco valor é dispensado às produções subjetivas dos servidores. Diante dessas lacunas e procurando promover a reflexão sobre o gerencialismo na administração pública brasileira, optou-se neste trabalho pela teoria da subjetividade de Rey (2003).

A partir dessa teoria, considera-se que embora a pesquisa esteja voltada para o espaço social do trabalho, não se desconsidera o processo dialético do sujeito com outras instâncias de sua vida. Assim, entende-se que a RFB é permeada pela subjetividade elaborada pelo servidor no âmbito familiar, pelas questões externas, como as econômicas, políticas e sociais, e pela própria subjetividade social na qual está instalada cada unidade.

Considerando as questões apontadas, o interesse desta pesquisa foi estudar os servidores que estão lotados em um órgão que desenvolve atividades específicas do Estado e que, após a implementação do modelo gerencial, vêm passando por mudanças, embasadas no entendimento de eficiência do mainstream. Para tanto, foi realizado um estudo de caso com analistas tributários e auditores fiscais da $6^{\mathrm{a}}$ Região Fiscal da Receita Federal do Brasil (RFB), em Belo Horizonte (MG).

O problema de pesquisa foi estabelecido a partir da seguinte questão: Como são organizados os sentidos subjetivos dos servidores da Receita Federal do Brasil em um órgão que tem investido no aprimoramento do modelo gerencialista? O objetivo foi compreender as configurações subjetivas compartilhadas pelos servidores da RFB decorrentes de sua atuação em um espaço de trabalho marcado pela hegemonia da ideologia gerencialista.

Além desta introdução, este trabalho encontra-se dividido em sete partes. Na segunda aborda-se o início da Reforma do Estado na Grã-Bretanha e nos Estados Unidos, a influência dela nos países em desenvolvimento e a implementação da Reforma no Brasil. Na terceira discute-se o conceito de ideologia gerencialista. $\mathrm{Na}$ quarta realiza-se uma articulação entre ideologia e teoria da subjetividade, enfocando o conceito de configurações subjetivas. Em seguida, focaliza-se a apresentação da epistemologia qualitativa, elaborada por Rey (2003, 2005), e as orientações metodológicas que moldam o estudo realizado. Na sexta discorre-se sobre a organização das informações produzidas, com base nas conversações realizadas. Nas considerações finais, aponta-se as principais inferências advindas das reflexões dos sujeitos de pesquisa em relação ao gerencialismo, 
indica-se as limitações do estudo, as contribuições da pesquisa e as sugestões para os trabalhos futuros. Por último, temos as referências que embasaram este trabalho.

\section{Reforma do Estado no Mundo e no Brasil}

O fim da década de 1970 é o marco de uma crise do Estado do bem-estar social. Foi nesse período que novos modelos advindos das organizações privadas começaram a emergir, fortalecendo a questão da competividade como requisito de sobrevivência no sistema capitalista (Machado-da-Silva, Guarido, Nascimento, \& Oliveira, 2005). Surgiu, então, um movimento amplo de reformas de Estado e de reformas administrativas em vários países (Carvalho, 1997).

No âmbito internacional diferencia-se duas gerações de propostas de reforma do Estado. A primeira envolveu a Grã-Bretanha, com a eleição da primeira-ministra inglesa Margareth Thatcher, e os Estados Unidos, com a do presidente Ronald Reagan. Para esta geração, as reformas envolviam a diminuição de custos e a ampliação da eficiência do setor público. Buscou-se o ajuste fiscal, por meio de redução dos gastos públicos, reformas tributárias, liberalização da economia, desregulamentação e privatizações. Essas reformas estavam embasadas na noção do Estado mínimo. Já a segunda geração foi desenvolvida na década de 1990 por meio da incorporação de outras propostas, como aquelas que buscavam fortalecer a capacidade gerencial do Estado, melhorar a qualidade dos serviços da administração pública e solidificar a accountability (Andriollo, 2006).

$\mathrm{O}$ modelo de reestruturação do Estado e da administração pública proposta pelo Reino Unido transformou-se em referência para outros países, principalmente para aqueles que se encontravam sob seu círculo de influência e que não apresentavam um welfare state consolidado (Paula, 2005).

No Brasil, com a eleição do presidente Fernando Henrique Cardoso (1995-2002) e a nomeação do economista Luiz Carlos Bresser-Pereira para o Ministério da Administração e Reforma do Estado (MARE), ocorreu uma ampla difusão dos princípios do gerencialismo (Bezerra \& Fernandes, 2013). Durante a administração de FHC o discurso enfatizava a necessidade de implementar uma reforma no país, buscando melhorias na administração pública, conforme apresentado no Plano Diretor do Aparelho do Estado (PDRAE). Este dividiu a administração pública em quatro eixos: Núcleo estratégico, Atividades exclusivas, Serviços não exclusivos e Produção de bens e serviços para o mercado. Salvo as organizações consideradas como de "produção de bens e serviços para o mercado", que seriam repassadas para o mercado, todos os outros eixos deveriam adotar o modelo gerencial.

Além dessas questões, a reforma gerencial de 1995 poderia ser considerada em dois ângulos, o estrutural e o da gestão. Em relação ao plano estrutural, com a caracterização dada pela reforma gerencial do núcleo estratégico do Estado no PDRAE, houve a valorização das carreiras de alto nível que integravam esse núcleo (Bresser-Pereira, 2008). De acordo com Campelo (2010), a valorização voltava-se também para a questão técnica e a profissional dos servidores, com alterações no plano de carreira, de modo que alcançassem a efetividade da gestão gerencial. Para tanto, os servidores precisavam possuir preparo técnico para acompanhar as novas necessidades operacionais e estratégicas. Em relação ao aspecto estrutural, foram criadas as agências executivas e as Organizações da Sociedade Civil de Interesse Público (OSCIP) (Bresser-Pereira, 2008; Bresser-Pereira, 2017).

Já em termos de gestão, várias organizações públicas buscaram preparar "planos estratégicos" voltados para uma "administração por resultados". Foi possível visualizar a implementação de sistemas de gestão embasados na motivação dos servidores públicos em relação ao alcance das metas ou de melhor desempenho. Além disso, ocorreram mudanças em relação às formas de responsabilização (accountability) (Bresser Pereira, 2008).

Várias críticas foram levantadas sobre o modelo gerencial na administração pública brasileira. Para Paula (2005), buscando o aumento da eficiência, a nova administração pública defendia a ampliação do poder discricionário dos burocratas e a elaboração de regras para a tomada de decisão, o que levou o interesse 
público a ficar em segundo plano a partir do momento em que estimulou o individualismo do decisor. A nova administração pública ampliou o isolamento dos decisores e expandiu as práticas personalistas e voluntaristas.

O gerencialismo contribuiu para o estabelecimento de uma cultura administrativa voltada para o empreendedorismo. $\mathrm{O}$ movimento se fortaleceu permeado pelas seguintes crenças: $\mathrm{O}$ progresso social decorria da contínua e crescente produtividade econômica, o management era fundamental para o planejamento e para a realização de melhorias em torno da produtividade e os gerentes possuíam o direito de administrar, o uso de tecnologias mais avançadas de organização e informação elevava a produtividade, e a implementação da tecnologia deveria estar relacionada a uma força de trabalho disciplinada de acordo com os princípios da produtividade (Paula, 2005).

Considerando as questões acima, destaca-se, de acordo com Rey e Martínez (2017a), que, diante dos grandes avanços proporcionados pela tecnologia na segunda metade do século passado, a reciprocidade de desenvolvimento entre subjetividade e cultura tornou-se mais intensa, tecnologia que possibilita a repressão e a emancipação, conforme o sujeito elabora sua própria realidade ao interagir ao lidar com esta. Para Paula (2013), o sujeito pode deixar-se dominar pelas tecnologias ou fazer destas a libertação das opressões do trabalho. Para tanto, é necessário analisar as manifestações decorrentes da tecnologia como uma construção social.

Ainda, de acordo com Zwich, Teixeira, Pereira e Vilas Boas (2012), ocorreu uma ressignificação daquilo que veio do exterior, mas sem compreender a crítica do que seria necessário para o Estado e a sociedade. O modelo gerencial não conseguiu resolver de forma adequada os problemas socioeconômicos do Brasil (Matias-Pereira, 2008).

Costa (2011) lembra que a reforma gerencial proposta por Bresser-Pereira demorou três anos para ser aprovada em regime pelo Congresso Nacional, após várias emendas na Constituição. A importância dessa reforma ocorreu especialmente no aspecto ideológico, como ressaltado por Bresser-Pereira durante um seminário, em termos da aceitação de uma administração pública embasada nos resultados gerenciais. É a partir desse ponto que se encaminha para a discussão do gerencialismo enquanto ideologia, conforme discutido abaixo.

\section{IDEOLOGia Gerencialista}

Foi a partir do século XVIII que a administração das pequenas firmas e empresas cresceu. A gestão instalou-se como uma forma de conhecimento especializado para as indústrias. No decorrer do século $\mathrm{XX}$, com a administração científica nos Estados Unidos, a administração das fábricas transformou-se em gestão. Posteriormente, esta adotou algumas ideologias, como "competição", "eficiência", "livre mercado" e "necessidade de ganhar dinheiro", transformando-se em gerencialismo, perspectiva que hoje afeta toda a sociedade (Klikauer, 2013b). Portanto, a gestão surgiu antes do gerencialismo (Klikauer, 2013a).

O qualitativo passou a ocupar um espaço junto ao quantitativo, a otimização, seguindo a maximização, e o entendimento de produtividade modificaram a concepção de rendimento. Além disso, a formação nas organizações passou a ser correlacionada com o crescimento da produtividade, buscando o ajuste na função dos trabalhadores para que estes se tornassem mais eficazes e produtivos (Tragtenberg, 1979).

A soma da gestão e da ideologia, assim como sua expansão, corresponde ao "gerencialismo". O "ismo" que se acrescentou à gestão representa uma doutrina de várias crenças e práticas ideológicas comuns. Para transformar a gestão em uma ideologia, o gerencialismo, primeiramente, precisa possuir uma ideologia própria (Klikauer, 2013b).

As políticas de reformas voltadas para o mercado, como "thatcherismo", racionalismo econômico e neoliberalismo, cresceram alinhadas com o gerencialismo. Entretanto, o gerencialismo e neoliberalismo não são sinônimos. Em suma, o gerencialismo não está preocupado com as questões do livre mercado do neoliberalismo. Seus princípios norteadores são a gestão e as técnicas de gestão utilizadas nas empresas. 
Contudo, o gerencialismo está acima da soma das técnicas de gestão, sendo que, para seu entendimento, é preciso considerar as influências sociais, econômicas e políticas. Já o neoliberalismo é centrado na desregulação e conquista de novos mercados, na desregulação do mercado de trabalho e das relações industriais, na redução do Estado de bem-estar social, na privatização, na diminuição da regulação estatal e no enfraquecimento dos sindicatos (Klikauer, 2013a).

$\mathrm{Na}$ administração pública, o gerencialismo tem a capacidade de provocar mudanças no ambiente organizacional, trazendo um conjunto negativo de efeitos psicossociológicos, tais como estresse, adoecimento, insatisfação, baixa motivação, medo e ressentimento. Ainda pode levar ao aumento da competitividade, da desconfiança, das tensões e de formas de violência simbólica, entre outros (Diefenbach, 2009).

Gaulejac (2007) entende que, a partir de uma apresentação objetiva, operatória e prática, o gerencialismo pode ser considerado uma ideologia que exprime as atividades dos trabalhadores por meio de indicadores de desempenho, e estes desempenhos, em despesas ou em benefícios. Também é construída uma representação do trabalhador como um recurso que está a serviço da organização, colaborando para sua instrumentalização.

Ressalta-se que em termos de subjetividade, a ideologia gerencialista não necessariamente condiciona o sujeito aos seus princípios. Outros modos de reflexão e ação podem ser construídos pelos sujeitos em seus momentos de criatividade. À vista disso, procura-se estabelecer no próximo tópico um diálogo com a teoria da subjetividade a fim de entender o emaranhado de sentidos e práticas que um sujeito é capaz de organizar em confronto com a ideologia.

\section{Ideologia e a Teoria da Subjetividade}

Originalmente, a palavra ideologia estava relacionada ao estudo científico das ideias humanas. Não tardou para que o objeto excedesse a abordagem, passando ao entendimento dos próprios sistemas de ideias. Posteriormente, foi possível perceber que a palavra ideologia possuía uma riqueza de significados que nem sempre eram compatíveis, assim, transformá-la em uma única definição tornou-se difícil (Eagleton, 1997).

Neste trabalho, entende-se que a ideologia é uma das formas de expressão social que possibilitam a perpetuação e legitimidade de processos institucionais dominantes. A ideologia como manifestação da subjetividade na vida social possui intensa mística e apoia-se em conjuntos de crenças de enorme valor afetivo (Rey \& Martínez, 2017).

A ideologia é configurada pelo sujeito, não sendo apenas algo externo ao indivíduo e não é estruturante, apesar da existência de formas hegemônicas de subjetividade social (Rey \& Martínez, 2017). Por subjetividade social Rey e Martínez (2017,p. 7) afirmam que esta "não é um suprassistema que atua como determinante de suas múltiplas configurações parciais singulares”, é o modo pelo qual as diversas configurações de espaços sociais e ordens distintas se organizam subjetivamente em cada um dos espaços sociais, em seus processos constituintes e nas pessoas que estão interagindo nesses espaços. Assim, como explica Rey (2005):

\footnotetext{
Um dos processos mais interessantes de produção de sentidos subjetivos é a naturalização dos espaços e dos fenômenos socialmente construídos. Nessa direção, os fenômenos da subjetividade social, ao se institucionalizarem, naturalizam-se, passando a ser realidades que se antecipam e que se impõem aos protagonistas das relações concretas que têm lugar em um espaço social. Assim, por exemplo, em qualquer instituição, as pessoas compartilham, no interior do espaço social instituído, uma série de códigos explícitos e implícitos em suas diversas práticas sociais, as quais se convertem em "realidades" socialmente aceitas que só serão transformadas pela ação crítica e diferenciada dos sujeitos concretos que vivem nessa realidade (p. 25-26).
}

Cabe ressaltar sobre a discussão acima que os atos e os posicionamentos não se separam das configurações subjetivas, sejam esses da condição de sujeito ou de agentes (Rey \& Martínez, 2017b). Para Rey (2003), a experiência do sujeito é constituída por vários elementos de sentido, advindos de diversas experiências, que produzem o sentido subjetivo da ação momentânea elaborada. A soma dessas experiências o autor nomeia 
de "configuração subjetiva". Por esse termo pode-se entender a associação dos elementos de sentido, que surge perante uma atividade em distintos espaços da vida. Assim, "todo conteúdo da experiência aparece subjetivado em configurações” (Rey, 2011, p. 39). A configuração seria um feixe complexo de sentidos que não podem ser examinados parte a parte, visto que interagem dialeticamente.

As configurações exprimem o sentido subjetivo dos distintos acontecimentos e processos da realidade social vivenciados pelo sujeito. Ou seja, a produção de sentido para o sujeito ocorre a partir de suas ações no convívio social, proporcionando outros focos de subjetivação decorrentes da tensão e da ruptura com aquelas configurações da subjetividade social que fizeram parte da sua constituição (Rey, 2003), perspectiva que orienta os procedimentos metodológicos descritos abaixo.

\section{Procedimentos Metodológicos}

A epistemologia qualitativa possui um caráter construtivo e interpretativo do conhecimento. Ou seja, não busca o conhecimento como apropriação linear de uma realidade apresentada, mas uma compreensão desta (Rey, 2005). Deste modo, afasta-se do entendimento de que somente o uso de processos dedutivos embasados no referencial teórico e de processos indutivos decorrentes da ação dos dados possibilita compreender a subjetividade (Martínez, 2005).

A metodologia desenvolvida por Rey, alinhada com a epistemologia qualitativa, entende que os percursos da vida pessoal e coletiva, as crenças, os valores e os preconceitos se inserem de modo bastante frequente no discurso científico e na maneira de elaborar o conhecimento. Com isso, o pesquisador percorre um caminho em sua vivência pessoal e profissional que "abre espaço para a sua aproximação com a realidade, pois esse, como ser de história única e detentor de uma subjetividade, constitui-se como sujeito ímpar na redefinição de proposições e na visão de novas possibilidades a serem construídas e transformadas" (Arrais, 2005, p. 65).

Para Rey (2011), a produção de conhecimento na pesquisa qualitativa é caracterizada pela consideração com o papel singular do estudado, demonstrado na legitimidade conferida ao estudo de caso. Considerando a perspectiva desse autor, foi realizado um estudo de caso com analistas tributários e auditores fiscais da $6^{a}$ Região Fiscal da Receita Federal do Brasil lotados na cidade de Belo Horizonte (MG). Ao todo, a RFB possui 599 unidades e emprega 9.974 auditores e 6.967 analistas no País (RFB, 2017).

A escolha da instituição justifica-se por esta ser alvo das políticas gerencialistas desde a implementação do modelo gerencial no governo FHC. Com a publicação do PDRAE a RFB passou a integrar as atividades típicas do Estado. Santos (2014) informa que a concepção do núcleo estratégico levou à estruturação de suas carreiras, que deveriam se orientar pelos princípios do gerencialismo.

A nova ideologia trazida para o serviço público com o modelo gerencial provocou mudanças em relação às tecnologias de gestão e à estruturação da RFB aos processos de trabalho, com a adoção de novas ferramentas tecnológicas, especialmente as relacionadas à informação das atividades (Oliveira, 2010). A RFB vem adotando conceitos alinhados às propostas do modelo gerencial de Bresser-Pereira, como as expressões "cliente", em substituição a "contribuinte", e "gestores" em substituição a "chefes" (Bianco, Colbari, \& Silva, 2010).

Neste sentido, a escolha de um órgão público merece destaque para a realização desta pesquisa, visto que, conforme salienta Klikauer (2013a, 2013b), este, assim como as instituições de ensino, trata-se de uma área em que o gerencialismo tem se destacado. Além disso, como adverte Ramos (1970), é fundamental sempre repensar os conceitos e pressupostos para a administração pública.

Após a escolha do órgão a ser pesquisado, a primeira tentativa de contato com o campo para a formação de um possível cenário social de pesquisa ocorreu em janeiro de 2016, com a presidente da Associação dos Auditores Fiscais da Receita Federal, mas não houve um retorno sobre a participação na pesquisa. Para Rey (2005), o "cenário social de pesquisa” é a criação do espaço no qual o estudo será desenvolvido e que buscará 
o envolvimento dos participantes. É no processo de criação desse cenário que os sujeitos decidirão se querem colaborar com a construção da informação e que o pesquisador conseguirá a confiança necessária.

Posteriormente, por meio de uma indicação, foi realizado contato com um auditor da RFB. A conversa com este servidor foi importante para construir os primeiros questionamentos, ter um melhor conhecimento da estrutura da RFB em Belo Horizonte e indicar alguns servidores que poderiam contribuir com a pesquisa. O encontro corroborou para a confirmação da primeira hipótese levantada: $\mathrm{O}$ gerencialismo estava presente na RFB, apesar do afastamento da academia em relação a esse tema após o término do Governo FHC. Tal pressuposto advinha da própria percepção da pesquisadora enquanto servidora pública e das leituras sobre o órgão pesquisado.

Em seguida foi marcado um encontro com outro auditor. Este momento foi um passo importante na pesquisa, visto que, com a maior inserção da Receita, oportunizado por ele, pôde-se dialogar com outros servidores. Aos poucos, foi possível conhecer novos analistas e auditores, o que permitiu a troca de ideias em relação ao tema da pesquisa.

No decurso desse processo e depois de conversar com vários analistas e auditores, a autora conseguiu definir aqueles servidores que tinham alguma relação com o tema e que queriam participar da pesquisa, conforme sugere Rey (2003). Dentre esses servidores, seis foram escolhidos, considerando a motivação em tratar sobre o tema abordado. No total, foram realizados dezoito momentos empíricos.

As conversações foram realizadas no período de agosto de 2016 a novembro de 2017. Como sugere a opção metodológica escolhida, foi-se para o campo aberta para utilizar os instrumentos, iniciando por uma conversação individual, considerando que o horário de trabalho de auditores e analistas e o local em que eles estavam lotados dificultavam a realização de um grupo de conversação. Além dessa questão, notou-se uma dificuldade para realizar conversações em grupo.

As conversas, em sua maioria, aconteceram na própria sede da Receita, em recintos reservados. A partir da proposta da metodologia construtivo-interpretativa, as conversações foram gravadas e transcritas para a construção dos indicadores. No momento empírico, algumas perguntas orientaram a dinâmica das conversações, buscando que o tema da pesquisa circulasse entre os participantes.

Cabe ressaltar que os indicadores são significados levantados pelo pesquisador diante das informações analisadas. $\mathrm{O}$ conflito de distintos indicadores frente a um determinado significado possibilita a construção de hipóteses que, ao se correlacionarem, definem o modelo teórico. Este não tem como proposta utilizar a priori os conceitos da teoria adotada, mas avançar no conjunto das informações analisadas a partir das hipóteses construídas. As hipóteses representam construções que possibilitam a ligação entre o emaranhado sistema de informações, ideias e reflexões e conduzem ao modelo teórico em uma pesquisa (Rey, 2010).

Por conseguinte, durante a organização das informações foi possível levantar os sentidos subjetivos e tecer inteligibilidade sobre as configurações que emergiram a partir da complexidade do conhecimento produzido e que estavam relacionadas ao gerencialismo na administração pública. Neste trabalho, a construção das configurações subjetivas ocorreu a partir da organização dos sentidos subjetivos, considerando que se apresentaram nas expressões dos auditores e analistas. Estes possibilitaram a formação de eixos de sentidos que deram origem às configurações. Ou seja, diferente da categoria, as configurações não podem ser analisadas separadamente, visto que estas interagem dialeticamente.

Os questionamentos levantados durante as conversações estavam relacionados às propostas da Reforma do Estado no Brasil (Bresser-Pereira, 2008, 2010, 2017) e ao conceito de gerencialismo construído por Klikauer (2013a, 2013b) e Gaulejac (2007). Participaram da pesquisa três auditores e três analistas. Os participantes foram informados sobre o objetivo da pesquisa e o sigilo quanto às informações e assinaram o "Termo de Consentimento Livre e Esclarecido". Todos os participantes tinham acima de 45 anos de idade e mais de 15 anos de instituição, conforme descrito a seguir: 
- Camila é analista tributária. Possui duas graduações, uma delas em Direito, realizada depois que começou a trabalhar no órgão,além de duas pós-graduações lato sensu. Era docente antes de passar no concurso da RFB. Também trabalhouem algumas empresas privadas.

- Fernanda é analista tributária. Além do curso superior, tem uma pós-graduação lato sensu. A escolha pelo órgão deu-se diante da dificuldade que as mulheres formadas em sua área têm para conseguir um lugar no mercado de trabalho na época de recém-formada.

- Paula é analista tributária e possui uma graduação e uma pós-graduação lato sensu. Antes de ingressar na RFB, trabalhou como autônoma e em algumas empresas privadas.

- Jonas trabalha como auditor fiscal. Esteve vinculado a autarquias e órgãos públicos antes de entrar na RFB. Além da graduação, possui duas pós-graduações lato sensu.

- Marcos é auditor e entrou na RFB em busca de maior segurança profissional e da integralidade na aposentadoria. Trabalhava na iniciativa privada antes de entrar no órgão federal. Fez uma segunda graduação em Direito após o ingresso na RFB e tem uma pós-graduação lato sensu.

- Eduardo é auditor fiscal. Trabalhou em uma autarquia estadual antes de ingressar na RFB. Possui duas graduações e duas pós-graduações lato sensu. A graduação em Direito foi iniciada após o ingresso na RFB.

$\mathrm{Na}$ seção seguinte apresentam-se as conversações que possibilitaram a construção do conhecimento. Ressalta-se que os nomes dos participantes foram trocados para preservar a identidade dos sujeitos.

\section{Análises e Resultados da Pesquisa}

Ao longo do percurso da pesquisa foi possível observar na fala dos servidores a complexidade da produção de sentidos relacionados ao gerencialismo. Seguindo a proposta de Rey (2005), as configurações subjetivas não foram construídas a partir da recorrência nas falas dos sujeitos participantes, mas à profundidade e à qualidade dessas expressões. Nesse processo de construção da informação, apresentaram-se cinco configurações subjetivas principais: Competitividade por atribuições, bônus produtividade, filiação sindical, mudança tecnológica, insatisfação na RFB.

\section{Competitividade POR ATRibuições: "Dividir PARA conQuistaR”}

Durante a realização da pesquisa estava ocorrendo o mapeamento dos processos para a reestruturação dos cargos da RFB. Essa prática, segundo os participantes, iniciou-se em 2014.

Fernanda demonstrou ser uma das servidoras mais envolvidas com as mudanças em torno das atribuições. Para ela, verificar como funcionam os processos não estava sendo nada fácil, pois a $6^{\text {a }}$ Região da RFB estava tentando mudar os auditores para as funções consideradas de maior inteligência. Os analistas ocupariam cargos logo abaixo e os demais servidores administrativos estavam sendo deslocados para outras atividades. Já os analistas advindos da Previdência, quando a RFB incorporou a Receita Previdenciária no Governo Lula, seriam realocados para cargos similares aos analistas da Receita.

Era difícil para um auditor que estava perto da aposentadoria e que trabalhava tirando senha agora ter que fazer um auto de infração, posto que não possuía mais domínio da legislação. Para ela, as pessoas precisariam receber treinamento para ocupar os espaços corretos, considerando que passaram no concurso para isso. " $\mathrm{Na}$ minha percepção, a gente não sabe gerenciar pessoas ainda. A gente não tem esse pulso forte, sabe, essa visão de mercado. Tem que ser assim e pronto!". Nota-se que os sentidos que Fernanda estabelece para a melhoria dos processos da RFB estão alinhados com a iniciativa privada. No início da pesquisa demonstra a incorporação dos preceitos da Reforma do Estado para a administração pública, conforme exposto por Bresser-Pereira $(2008,2010,2017)$. Outro ponto a ser apontado é que Fernanda ocupava um cargo de chefia dentro da RFB. 
Como afirma Klikauer (2013a), pessoas na posição de gerência inclinam-se aos valores gerenciais como algo habitual.

Camila, em seu processo de subjetivação, elabora sentidos associados às perdas de direitos e atividades. Várias atividades que os analistas faziam há anos estavam sendo retiradas, dado que eram os auditores responsáveis pela elaboração das portarias, instruções normativas e ordens de serviço. Mas, por vezes, quando constava do documento algum trabalho que os auditores não gostavam de realizar, os analistas eram demandados para tal tarefa. A fala de Camila demonstra que as divergências na RFB estavam relacionadas às decisões de um pequeno grupo da alta administração, que desconsiderava o diálogo com os envolvidos.

$\mathrm{Na}$ visão do Marcos, os analistas sempre foram próximos da administração. "Aí vem aquela regra do Júlio César: Dividir para conquistar”. Por isso, quando os auditores faziam greve, a categoria dos analistas não aderia. No passado, ambos os cargos se juntavam e, então, a RFB parava de verdade. A partir de 1995, com o governo FHC, houve um distanciamento entre as duas categorias. É interessante notar que Marcos delineia o momento em que houve um distanciamento entre os dois cargos da carreira tributária. O período dessa fragmentação entre os servidores aconteceu a partir do momento em que a administração pública brasileira se voltou para o modelo gerencial.

Observando a fala dos analistas e auditores acima, pode-se dizer que a competição e a rivalidade (Klikauer, 2013a; Machado-da-Silva et al., 2005), em detrimento da coletividade, participação e cooperação, conforme apresentado no PDRAE (Brasil, 1995), é uma característica da ideologia gerencial que sobressaiu na configuração subjetividade "competitividade por atribuições", demarcando o espaço social da RFB e a subjetividade social dos servidores.

\section{Bônus PRodutividade: "Um CAVAlo DE Troia"}

Além do mapeamento acima mencionado, estava sendo discutida no Congresso Nacional uma nova forma de remuneração dos servidores, o bônus de eficiência e produtividade. Jonas explica que a ideia do bônus foi alçada pela presidente Dilma Rousseff, no início de 2016. Os auditores estavam insatisfeitos com um Projeto de Emenda Constitucional que sugeria a vinculação de várias categorias ao salário dos Ministros do Supremo Federal. Os auditores foram excluídos desse projeto e instauraram uma greve que durou sete meses.

Segundo Jonas, existiam duas categorias na RFB: Os ativos e os inativos ou pensionistas. Entre os ativos, a RFB poderia ser dividida em três gerações quando se trata da aposentadoria: Os servidores que ingressaram até 2003, que teriam direito à paridade; aqueles que entraram após essa data e se aposentam de acordo com a média das contribuições corrigidas pela inflação; e os servidores que tomaram posse a partir de 2012, após a criação da Fundação de Previdência Complementar do Servidor Público Federal do Poder Executivo, os quais receberiam pelo teto do Instituto Nacional do Seguro Social (INSS) e mais uma complementação paga pelo fundo.

Com o bônus, acrescenta Jonas, houve uma quebra da paridade entre os servidores mais antigos. De início, a bonificação não seria paga aos inativos ou pensionistas. Mas, o governo entendeu que o resultado do trabalho do auditor somente seria visto depois de alguns anos, devido à demora do processo administrativo. Com isso, estabeleceu-se uma escala, na qual o inativo começaria recebendo $100 \%$ do bônus até atingir 30\%, após dez anos. Tal fato levou os inativos a serem contrários ao bônus, porque rompia com a paridade. Já os mais novos, como não tinham nenhuma perspectiva nesse sentido, foram a favor da proposta. Como os inativos tinham direito ao voto, houve uma divisão por faixa etária dentro da categoria.

Jonas acredita que, com a reforma da Previdência em discussão no Congresso Nacional, os ativos perderiam ainda mais direitos. Então, com isso, os servidores em atividade nunca mais iriam defender os inativos. "A partir dessa divisão que houve, vamos inserindo, digamos, um cavalo de Troia no sindicato e, a partir desse momento, nada será como antes". Nota-se que no sentido abordado por Jonas, em termos da Reforma da Previdência, como destacado por Klikauer (2013a, 2013b), o gerencialismo ultrapassa as técnicas de gestão. 
Este também é influenciado por questões sociais, econômicas e políticas. Assim, questões que tratam sobre educação, saúde e previdência são comuns nos debates gerencialistas.

Por meio da metáfora do cavalo de Troia que Jonas levanta, percebe-se que os auditores, assim como os troianos, de início, conceberam o bônus como a esperança de uma vitória em termos de valorização salarial e, quem sabe, até de maior eficiência e produtividade do órgão. O que esses servidores não presumiram é que dentro do cavalo, nomeado "bônus", uma "vislumbrante" ferramenta de gestão da iniciativa privada, estavam as fissuras que enfraqueceriam a carreira. Do eufemismo do bônus a partir do mito da Guerra de Troia, emerge na fala de Jonas um sentido associado à decepção, visto que, ao seduzir ativos e inativos, pelo menos no início da discussão, este desmantelou os laços até então estabelecidos.

Como Jonas, Marcos acreditava que, com essas mudanças, a categoria ficou fragmentada em vários pedaços. Nota-se que a subjetividade social gerada a partir da proposta do bônus produziu e ampliou a insatisfação com a remuneração, desviando os servidores da coletividade. Esta perspectiva induziu os ativos e os inativos à defesa de orientações individualistas ou restritas aos grupos. Ao que parece, considerar o servidor aposentado tal como o da ativa representava aquilo que Rey (2005) chama de “código explícito”. No caso da Receita, esse preceito transformava ativos e aposentados em "nós". À medida que os interesses pessoais crescem no órgão, os sujeitos começam a criticar e romper como esse entendimento.

Paula defende que a política do governo não era uma afronta à valorização dos servidores da RFB, mas aos aposentados, levando em consideração que ao longo dos anos a RFB incorporou ativos e aposentados de vários órgãos que foram extintos, como por exemplo, os servidores do Instituto Brasileiro do Café. O benefício de aposentadoria dessas pessoas estava vinculado aos servidores da ativa da RFB. A analista explica que a paridade em termos legais foi extinta. Entretanto, existiam aqueles servidores com direito adquirido. O bônus seria uma alternativa para não desprestigiar o núcleo de carreiras típicas, mas dar outro tratamento àqueles que usufruíam da paridade.

Pode-se dizer que a crítica que perpassa a fala de Paula estava relacionada aos conceitos difundidos no PDRAE. Já naquela época, havia uma preocupação com o crescente número de inativos, quando comparado com o número de ativos. Para o Governo FHC, em termos fiscais, a Previdência ficaria insustentável, como apresentado no Plano Diretor: "A União terá de incorrer em déficits crescentes, ou comprimir ainda mais os gastos com salários dos servidores em atividade e as despesas com consumo e investimento para arcar com o pagamento de aposentadorias". A reforma da previdência do funcionalismo era um ponto chave para orientar a questão fiscal e a reforma do Estado (Brasil, 1995, p. 32).

É importante destacar que o bônus produtividade, enquanto uma ferramenta gerencialista objetiva, não estabelece as configurações subjetivas. O que este estudo buscou demonstrar é que os sujeitos conseguem elaborar sentidos diversos em relação a este tipo de bonificação. Ou seja, "a subjetividade não é um reflexo de uma condição objetiva, mas a capacidade de produzir alternativa frente à experiência vivida a partir dos recursos subjetivos atuais da pessoa" (Rey, 2010, p. 343).

\section{FILIAÇÃO SINDICAL: "O SERVIDOR NÃO EXISTE SEM ELE"}

Quando entrou na RFB, Camila filiou-se ao sindicato. Entretanto, começou a questionar como essa entidade funcionava. Diante disso, resolveu afastar-se por um período. "Eu comecei a participar bem de perto [do sindicato] e me incomodava bastante como [ele] funcionava", segundo Camila. Naquele momento da primeira conversação, em 2016, a analista tinha voltado a participar, porque pensava que, apesar das críticas, "o servidor não existe sem ele". Ou seja, o sindicato possibilitaria o respeito dos analistas em relação aos problemas que afloravam na RFB.

Para Eduardo, o sindicato era o "o mal necessário". Sem o sindicato os trabalhadores não conseguiam qualquer tipo de conquista. Em contraposição, via no discurso dos sindicalistas um corporativismo e considerava que muitas críticas feitas à administração da RFB não eram justas. Havia críticas justas, mas 
o que interessava aos sindicalistas era a perpetuação no poder: "O poder é um negócio que realmente corrompe", diz Eduardo. Era um problema da sociedade e o sindicato também padecia desse dissabor. Além disso, os sindicatos adotavam um viés eleitoral e, por vezes, estabeleciam uma negociação considerando essa orientação. "O sindicato é o nosso instrumento, mas, normalmente, a gente acaba virando em certos momentos massa de manobra". Emerge na fala de Eduardo que o sindicato seria uma via para o diálogo com a alta administração, mas existia um distanciamento entre o interesse do sindicato enquanto uma entidade política e as necessidades dos servidores.

Ao contrário de Eduardo, Fernanda parece entender o sindicato não como uma entidade distante, destacando a importância coletiva na participação: "Eu acredito que o sindicato somos nós”. Para a analista, somente era possível representar de forma adequada os trabalhadores quando estes estavam presentes nas assembleias. "Então, como muitas pessoas como eu não iam, a gente não tem o direito de falar que o sindicato não nos representa". Para ela, muitas reclamações que as pessoas faziam contra o sindicato ocorriam por falta do engajamento delas: "Eu não posso falar que o sindicato não me representava bem, porque eu era uma alienada no processo. Agora, não!”. A reflexão de Fernanda leva ao entendimento de que, diante dos conflitos que ocorriam no órgão, ela despertou para os problemas da RFB, questões com as quais até então parecia não se importar.

Apesar de reconhecer a importância do movimento sindical para a sua carreira, Jonas acreditava que os resultados da entidade eram "modestos", mas quando visualiza de forma geral, achava a atuação do sindicato "medíocre". Alguns servidores utilizavam o sindicato como uma fuga das frustrações pessoais e profissionais, obtendo por meio do sindicato um status social. Outros utilizavam o sindicato para viagens, participação em congressos e relaçóes sociais. O sindicato era caro, pois possuía uma estrutura pesada, visto que os auditores contribuíam com $1 \%$ do salário, gerando em torno de $\mathrm{R} \$ 4$ milhões por mês. E, dependendo da causa, ainda era necessário fazer um fundo de mobilização adicional. Observa-se aqui que a concepção de sindicato elaborada por Jonas está relacionada às propostas de racionalidade do gerencialismo.

Ressalta-se que, ao produzir distintas subjetividades, o entendimento do sindicato é ressignificado pelos servidores, mas o que perpassa a subjetividade social é que analistas e auditores, mesmo sindicalizados, têm uma participação mínima na entidade e opinam pouco sobre as questóes que envolvem a carreira. Além disso, no espaço social onde a palavra era suprimida e limitada ao alto escalão da RFB e aos governantes os sentidos atribuídos ao sindicato estão relacionados a um caminho para superar o sofrimento advindo de um espaço social hostil, embora sobressaia nesse mesmo sindicato o fortalecimento do gerencialismo na RFB, como destacado por Bianco, Colbari e Silva Neto (2010).

\section{MudANÇA TECNOLÓGICA: "Só QUE O NOSSO PESCOÇO TAMBÉm ESTÁ NA CORDA"}

Rey e Martínez (2017) afirmam que, diante dos grandes avanços proporcionados pela tecnologia na segunda metade do século passado, a reciprocidade de desenvolvimento entre subjetividade e cultura tornou-se mais intensa. Durante o momento empírico deste trabalho, em termos da produção subjetiva dos participantes, vários sentidos foram gerados quando o assunto tecnologia foi levantado.

O temor em relação à tecnologia surge nos sentidos atribuídos por Fernanda em relação à informatização. A analista destacou que algumas rotinas no órgão estavam sendo automatizadas, o que demandava menos servidores para realizar certas tarefas. "O que mais coloca medo nem é a terceirização, é a informatização do processo de trabalho junto ao contribuinte", diz a servidora. Para a analista a tecnologia pode promover sentidos associados à dificuldade de utilizá-la e ao temor em relação a seus impactos no cotidiano do trabalhador e na manutenção do emprego. Assim, como exposto por Paula (2013), para Fernanda a tecnologia seria mais uma forma de opressão, em termos da extinção das atividades desenvolvidas na RFB e ao seu medo em relação a essa possibilidade. 
Camila enfatizou que a RFB trabalhava com cruzamento de dados. Com isso, o auditor fiscal de pasta acabaria virando o que ela chamou de "uma figura de museu". Não existia mais a possibilidade de visitar a empresa e verificar a contabilidade, considerando que as empresas enviavam as informações à RFB. Assim, os auditores estavam se sentindo ameaçados. Por isso, tentavam ocupar os lugares dos analistas, para terem uma segurança interna: "Só que o nosso pescoço também está na corda". A tecnologia estaria ganhando tanto espaço que em pouco tempo poderia representar praticamente todo o trabalho da RFB e o enxugamento do órgão era visto como uma possibilidade.

Além da informatização dos processos de trabalho, Jonas levantou ao longo das conversações a questão do treinamento. $\mathrm{O}$ auditor explica que até o início do governo FHC existia uma semana chamada "Programa do Imposto de Renda", em que todos os servidores se reuniam para que alguns auditores repassassem as mudanças da legislação do ano anterior e discutissem outros assuntos. Este era realizado pela Escola de Administração Fazendária e os servidores responsáveis pela capacitação recebiam um valor justo por horaaula, equivalente a sua remuneração. $\mathrm{O}$ auditor era pago pelo trabalho e pelo curso que ele realizava como instrutor. "Isso era um grande estímulo à participação dos colegas como instrutores. Então, eles faziam um curso no órgão central, depois repassavam isso com muito empenho e eram pessoas que... Quem escolheu fazer esse curso eram sujeitos competentes". Ou seja, em seu processo de subjetivação Jonas atribui sentidos à perda da efetividade da capacitação assim que a tecnologia foi estabelecida como referência no órgão.

Os sentidos elaborados por Jonas em relação à política de capacitação demonstram que a dialética e a dialogicidade presentes nos cursos presenciais foram afastados quando estes passaram a ser realizados no modo a distância. Acrescenta-se que os trabalhadores esbarram na dificuldade da "capacitação profissional contínua" em substituição à “capacitação permanente", decorrentes das mudanças tecnológicas, conforme lembra Tragtenberg (1989) sobre as demandas das organizações aos trabalhadores da sociedade capitalista.

Paula entendia que a RFB não ofertava formação para os servidores como na década de 1990. Naquela época, havia recurso para investir nas capacitações. Hoje, a verba era escassa. Quem era operacional tinha alguns treinamentos a distância, mas não chegava perto da época em que ela entrou na RFB. Além disso, os cursos estavam voltados para os gestores. Os cursos de coaching acabavam não provocando muitas mudanças. Os cursos de formação de um coach demonstram como a cultura do management (Paula, 2005) está estabelecida na administração pública brasileira, mas sem garantir a capacidade técnica que era apresentada no PDRAE, conforme destaca Campelo (2010). Além disso, conforme expõe Tragtenberg (1989), ao transformar funções técnicas, no caso dos auditores, em atividades gerenciais, preocupada com a produtividade da Receita, degenera-se a competência técnica desses profissionais.

\section{InsatisfaÇão na Receita: "Eu estava PREcisando SAIR DaQuele AMbiente”}

No começo da pesquisa, Fernanda argumentou que não estava feliz na Receita, mas que a presença dela era importante para ajudar a construir o órgão, por isso, não poderia aposentar naquele instante. Ela tentava estar presente de uma forma mais profissional possível por "amar" o local que trabalhava. "É um órgão que investe muito nas pessoas. Dá orgulho de trabalhar na Receita. A missão da Receita, pra mim, é meu gás, é minha energia”.

A decepção estava relacionada com o fato de os gestores estarem pensando neles mesmos e não observarem que o órgão estava parado. Apesar de enfatizar ao longo das conversações seu envolvimento com a Receita, emerge na fala de Fernanda uma forma de defesa individual para lidar com as questões que ela não concordava. "Eu tirei férias esses dias. Vou te falar... Eu estava precisando sair daquele ambiente. Aquele ambiente estava me fazendo mal".

A analista Camila precisou recorrer aos fármacos para superar aquele momento da sua vida: "Então, eu tenho feito uso de antidepressivos". Durante a pesquisa ela precisou aumentar a dose desses remédios para conseguir lidar com as diversas atribulações que ocorriam no âmbito individual na instituição: "Eu aumentei 
a minha dose de remédio. Estou no limite”. Através da fala da servidora sobre os efeitos psicológicos, neste caso, fica evidente o adoecimento que um espaço social marcado pelo gerencialismo provoca, conforme os estudos de Diefenbach (2009) demonstram.

Jonas sente-se insatisfeito em relação à carga tributária brasileira que era alta quando comparadaao padrão de desenvolvimento do país. Além disso, a legislação era complexa e de difícil aplicação, sobrecarregando as atividades internas. Os esforços despendidos pelos servidores levavam a poucos resultados. Apesar de não entrar nesse assunto, a contradição que Jonas encontra expressa parte do pensamento de Ramos (1970) no sentido de que os servidores públicos não podem ultrapassar aquilo que o meio político permite. Desse modo, o auditor pode estar se incluindo nesse sentido, visto que no seu dia a dia lida com a questão de grandes contribuintes que não são tributados de forma justa.

Para Marcos, embora no imaginário popular a administração pública seja um local tranquilo para trabalhar, a realidade era bem diferente. $\mathrm{O}$ auditor procurou enfatizar que, de toda forma, ele não poderia reclamar da RFB. Existiam elementos para serem melhorados, mas era possível ver aspectos positivos. Ao longo das conversações, sempre retomava a dificuldade de ocupar um cargo público no país, tentando balancear sua crítica por meio da comparação com os outros órgãos. Emergem na fala do participante sentidos relacionados ao desapontamento com a administração pública brasileira em geral e a representação da imagem do serviço público estabelecida na subjetividade social da população brasileira.

\section{Considerações Finais}

O objetivo do trabalho foi compreender as configurações subjetivas compartilhadas pelos servidores da Receita Federal do Brasil decorrentes de sua atuação em um espaço de trabalho marcado pela hegemonia da ideologia gerencialista. As cinco configurações subjetivas, competitividade por atribuições, bônus produtividade, filiação sindical, mudança tecnológica e insatisfação na RFB, apresentadas ao longo da pesquisa emergiram a partir das tensões e contradições que vêm surgindo com as políticas de gestão para a RFB.

Pode-se dizer, a partir das configurações acima, que no órgão pesquisado há um afastamento de formas colaborativas de trabalho. $\mathrm{O}$ modo como está sendo realizada a reestruturação da RFB demonstra as limitações dessas escolhas. Reestruturação que, segundo Klikauer (2013a), tornou-se um hábito nas organizações gerencialistas. Aliado a isso, o individualismo presente na subjetividade social do órgão dificulta a ruptura e a construção de propostas de gestão distintas do gerencialismo. A solidariedade torna-se mais difícil de ser construída diante das lutas corporativistas dos cargos da carreira tributária.

A insegurança perpassava a subjetividade social e individual dos analistas e auditores. Diante dessa questão, o bônus reforça esse sentido devido à quebra da paridade entre ativos e inativos. Entre as técnicas de gestão, o bônus não foi o maior dos problemas apontados pelos servidores. O que estava realmente em jogo era o valor simbólico dessa ferramenta, ou seja, de que modo ela atuava na "exclusão" e "desigualdade".

Contrapondo-se à visão hegemônica de linearidade própria dos valores gerencialistas, a RFB é um espaço de ambiguidades. Apesar das críticas apontadas, os participantes demonstravam certo "orgulho" por trabalhar no órgão, ou mesmo o "amor" à profissão, como destaca Fernanda. O vínculo de alguns servidores com tempo para se aposentar demonstra que estar na Receita representa mais do que uma questão financeira.

Ao ter boa parte das decisões centralizadas na alta administração da RFB e no Governo Federal, os servidores se veem angustiados em meio a um conjunto de leis, normas e procedimentos que rompem com a cultura construída ao longo da história do órgão. Ou seja, o entendimento hegemônico do gerencialismo é visto de modo proeminente em relação a outros modos de gestão. Tragtenberg (1989) afirma que o Estado pode incentivar o individualismo e não o indivíduo ao direcionar as suas políticas para o fortalecimento do primeiro. Segundo o autor, nas políticas de capacitação, um exemplo que pode ser verificado na RFB, as organizações valorizam o crescimento individual em detrimento do coletivo. 
O trabalho na Receita afasta-se da percepção de um espaço social diferenciado, devido à diversidade daqueles que compõem o órgão, ao se configurarem em grupos "atomizados”. A fragmentação do órgão em cargos, carreiras, gerações e gestores limita a mobilização em torno de alternativas internas e externas para a crise vivenciada. Soma-se a essa questão a divergência em relação à atuação dos sindicatos e à representação dessas entidades. Diante desses apontamentos, a contribuição deste trabalho está em entender que políticas governamentais e de gestão podem interferir no espaço social da administração pública. Ampliar o olhar é importante, visto que quase sempre gestão e políticas governamentais se entrelaçam. Uma limitação do estudo que poderia ter expandido esta discussão foi não ter entre os participantes servidores concursados em distintos momentos, visto que todos tinham direito à aposentadoria integral.

Por fim, é possível dizer, concordando com Rey (2003), que os próprios servidores da organização estudada são capazes de gerar uma nova RFB e, quem sabe, promover inteligibilidades para a administração pública. Nesse sentido, as autoras deste trabalho, que são todas servidoras públicas, acreditam que a administração pública precisa ser pensada para além das propostas atuais, principalmente nesse momento de grandes ataques aos direitos sociais da população e dos servidores que compõem a máquina pública. Para propiciar esse debate são imprescindíveis a união dos servidores e a emergência dos sujeitos enquanto seres criativos, apesar de, por vezes mergulhados nos conflitos, nem sempre isso ser fácil. Como afirma Klikauer (2013a), é difícil para as pessoas enxergarem um mundo diferente do gerencialismo, por isso o entendimento do qualitativo e das diferenças é um desafio na nossa sociedade.

\section{Agradecimientos}

Agradecimentos ao CNPQ pelo apoio financeiro que viabilizou a pesquisa que deu origem a esse artigo.

\section{REFERÊNCIAS}

Arrais, A. R. (2005). As configurações subjetivas da depressão pós-parto: para além da padronização patologizante. (Tese de Doutorado). Universidade de Brasília, Brasília, DF, Brasil.

Bianco, M. F., Colbari, A. L., \& Silva, A. O., Neto (2010). A categoria dos auditores fiscais da Receita Federal do Brasil: a (des) construção da identidade profissional. Cadernos EBAPE, 8(1), 453-467.

Brasil, Presidência da República. (1996). Uma estratégia de desenvolvimento social. Brasília. Recuperado de: http://w ww.planalto.gov.br/publica.htm.

Bresser-Pereira, L. C. (2008). Os primeiros passos da reforma gerencial do Estado de 1995. Revista Brasileira de Direito Público, (23)1, 145-186.

Bresser-Pereira, L. C. (2010). Democracia, Estado social e reforma gerencial. Revista de Administração de Empresas, 50(1), 112-116.

Bresser-Pereira, L. C. (2017). Entrevista: Luiz Carlos Bresser Pereira. Entrevista concedida a Amon Barros. BresserPereira e a reforma gerencial do Estado. Administração Pública e Gestão Social, 9(3), 237-247.

Carvalho, W. (1997). A reforma administrativa da Nova Zelândia nos anos 80-90: controle estratégico, eficiência gerencial e accountability. Revista do Serviço Público, 1(3), 5-35.

Costa, F. L. (2011). A nova elite dirigente e a modernização da administração pública. Aparelhamento, renovação ou corporativismo. Desigualdade \& Diversidade, Dossiê Especial, 107-118.

Diefenbach, T. (2009) New public management in public sector organizations: the dark sides of managerialistic “enlightenment". Public Administration, 87(4), 892-909.

Gaulejac, V. (2007). Gestão como doença Social. ideologia, poder gerencialista e fragmentação social. Aparecida: Ideias $\&$ Letras.

Klikauer, T. (2013a). Managerialism. a critique of an ideology. London: Palgrave Macmillan. 
Klikauer, T. (2013b). What is managerialism? Critical Sociology, 41(1), (7-8), 1103-1119.

Machado-Da-Silva, C. L., Guarido, E. R., Filho, Nascimento, M. R., \& Oliveira, P. T. (2005). Formalismo como mecanismo institucional coercitivo de processos relevantes de mudança na sociedade brasileira. Anais do 25 Encontro Nacional de Pós-Graduação e Pesquisa em Administração. (1-15). Campinas: EnANPAD.

Martínez, A. M. (2005). A teoria da subjetividade de González Rey: uma expressão do paradigma da complexidade na psicologia. In F. G. Rey (Org.). Subjetividade, complexidade epesquisa em psicologia. São Paulo: Pioneira Thomson Learning (1-25).

Misoczky, M. C., Abdala, P. R. Z, \& Damboriarena, L. (2017). A trajetória ininterrupta da reforma do aparelho do Estado no Brasil: continuidades nos marcos do neoliberalismo e do gerencialismo. Administração Pública e Gestão Social, 9(3), 184-193.

Oliveira, F. M. (2010). Uma análise da autonomia no trabalho dos auditores fiscais da Receita Federal do Brasil, no setor de fiscalização da delegacia da Receita Federal em Vitória-ES. (Dissertação de Mestrado). Universidade Federal do Espírito Santo, Vitória, ES, Brasil.

Paula, A. P. P. (2005). Por uma nova gestão pública. limites e potencialidades da experiência contemporânea. Rio de Janeiro: Editora FGV.

Paula, A. P. P. (2013). Avanços e Desafios Tecnológicos nas Organizações: uma abordagem construcionista e crítica. Revista Interdisciplinar de Gestão Social, 2(1), 137-160.

Paulilo, M. I. (2013). FAO, fome e mulheres rurais. Dados - Revista de Ciências Sociais, 56(2), 285-310.

Plano Diretor da Reforma do Aparelho do Estado. (1995). Elaborado pelo Ministério da Administração Federal e Reforma do Estado e Aprovado pela Câmara da Reforma do Estado e pela Presidência da República. Brasília, DF: MARE.

Ramos, A. G. (1970). A nova ignorância e o futuro da administração pública na América Latina. Revista de Administração Pública, 4(2), 7-45.

Rey, F. L. (2003). Sujeito e subjetividade. uma aproximação histórico cultural. São Paulo: Pioneira Thomson Learning.

Rey, F. L. (2005). Pesquisa qualitativa e subjetividade. os processos de construção da informação. São Paulo: Thomson.

Rey, F. L. (2010). As configurações subjetivas do câncer: um estudo de casos em uma perspectiva construtivointerpretativa. Psicologia Ciência e Profissão, 30(1), 328-345.

Rey, F. L., \& Martínez, A. M. (2017a). Subjetividade. teoria, epistemologia e método. Campinas: Editora Alínea. E-book. ISBN 978-85-7516-811-0.

Rey, F. L., \& Martínez, A. M. (2017b). El desarrollo de la subjetividad: una alternativa frente a las teorías del desarrollo psíquico. Papeles de Trabajo sobre Cultura, Educación y Desarrollo Humano, 13(1), 3-20.

Silveira, R. Z., Palassi, M. P., \& Silva, A. R. L. (2013). E a ponta fica excluída: desafios à participação do servidor na Administração Pública. Revista Org \& Demo, 14(1), 51-72.

Tragtenberg, M. (1989). Administração, poder e ideologia. São Paulo: Cortez.

\section{BY-NC-ND}

